\title{
Effect of astaxanthin on Strawberry Seedlings under low temperature stress on active oxygen metabolism
}

\author{
Meng Che ${ }^{1, a}$, Ya Luo ${ }^{1, b}$, Cong Ge ${ }^{1, c}$, Ya'jie Ling ${ }^{1, d}$, Qin Mo ${ }^{1, e}$, Shu Luo ${ }^{1, f}$ and \\ Hao'ru Tang ${ }^{1, g^{*}}$ \\ ${ }^{1}$ College of Horticulture, Sichuan Agricultural University, Chengdu, Sichuan, China \\ a1425226782@qq.com, b173698873@qq.com, c442477804@qq.com, d2208312818@qq.com, \\ e943156105@qq.com, '626567947@qq.com and 91048019614@qq.com
}

${ }^{*}$ Corresponding author. Meng Che, Ya Luo and Cong Ge contributed equally to this work.

Keywords: Astaxanthin; Strawberry; Low temperature stress; Active oxygen

Abstract: In order to solve the problem of low temperature damage in strawberry production, 'Benihoppe' strawberry (Fragaria ananassa Duch) was used as a material, so the effects of astaxanthin treatment on strawberry seedlings under low temperature stress was studies. The results showed that compared with the control, the antioxidant enzyme (SOD, POD, CAT, APX) activity and FRAP value of strawberry leaves increased; meanwhile the production rate of $\mathrm{O}_{2}{ }^{-}, \mathrm{H}_{2} \mathrm{O}_{2}$ and MDA were decreased in all astaxanthin treated strawberry seedlings under low temperature stress. Especially the treatment of $50 \mu \mathrm{mol} / \mathrm{L}$ astaxanthin had the best effect, indicating that the astaxanthin treatment in suitable concentration can effectively reduce the injuries in strawberry seedlings under low temperature.

\section{Introduction}

Low temperature is one of the main limiting factors affecting the growth, development and distribution of plants, and low temperature adversity leads to excessive production and accumulation of reactive oxygen species $\left(\mathrm{O}_{2}{ }^{-}\right.$and $\mathrm{H}_{2} \mathrm{O}_{2}, \mathrm{OH}^{-}$and et al), so as to aggravate the hyperoxidation of cell membrane lipids, denaturation of protein and nucleotide's injury, even leading to the death of cell ${ }^{[1]}$. When plant is under low temperature stress, its own will produce a series of defense mechanisms, such as anti-oxidation enzymes, anti-stress proteins and other substances to combat free radicals,so it can protect plants from reactive oxygen ${ }^{[2]}$, and enhance the resistance of plants to cold. Therefore, antioxidant metabolism plays an important role in protecting plants under low temperature stress. Astaxanthin is a carotenoid that is not a source of vitamin $\mathrm{A}^{[3]}$, and the important property is that it is extremely strong resistance to oxidation, many previous studies have shown that it is a good antioxidant, playing an important role in quenching free radicals ${ }^{[4,5]}$. Manys studies have been conducted on the use of astaxanthin for human medicine and livestock feed, and the use of biotechnology for the production of astaxanthina yet at present ${ }^{[6-8]}$. However there was little research about the effect of astaxanthin on the antioxidant activity and the metabolism of plant active oxygen.

Strawberry (Fragaria $\times$ ananassa Duch), is a perennial fruit tree crop, the fruit is soft, and juicy has rich nutrition. Its yield and cultivation area have always been the first in the production of small berries ${ }^{[9]}$. Because the protection facilities are poor, the short-term low temperature injury occasionally would occured in the strawberry cultivation process in winter, thus causing great loss to strawberry production. Based on the strong antioxidant properities of astaxanthin, this study was to explore the effecs of astaxanthin on active oxygen metabolism of strawberry seedlings under low temperature. 


\section{Materials and Methods}

Materials collection. In this experiment, the test-tube seedling leaves of 'Benihoppe ' were used as experimental materials. The test-tube seedlings were established and preserved by biotechnology of college of horticulture, Sichuan Agricultural Uiniversity in September 2016. The MS medium includes $1 \mathrm{mg} / \mathrm{L} \mathrm{BA}, 30 \mathrm{~g} / \mathrm{L}$ sucrose and $7 \mathrm{~g} / \mathrm{L}$ agar. The culture condition is $25 \pm 1^{\circ} \mathrm{C}, 2500 \mathrm{Lx}$ and daylight for 16 hours a day.

Experimental Design. Through preliminary pilot study, screening and determining the proper astaxanthin concentration in this study. First, the strawberry tube-seedlings were cultivated for four weeks, and then $0,5,10,50$ and $100 \mu \mathrm{mol} / \mathrm{L}$ astaxanthin were respectively added to the medium. After half a month of cultivating, the test-tube seedlings were put in incubator at $4^{\circ} \mathrm{C}$. After $0,3,6,12$, 24,48 hours in low temperature, the leaves were respectively cut from the seedlings, which were used to measure the relevant indicators, such as the superoxide dismutase (SOD), catalase (CAT) and peroxidase (POD) and ascorbic acid peroxidase (APX), FRAP and the production rate of superoxide anion $\left(\mathrm{O}_{2}{ }^{-}\right)$, hydrogen peroxide $\left(\mathrm{H}_{2} \mathrm{O}_{2}\right)$ and malondialdehyde(MDA) content. The experiment was repeated three times.

Statistical Analyses Statistical analyses were conducted using statistical software of SPSS 17.0. Data were analyzed by one-way ANOVA with least significant difference at $5 \%$ confidence level.

\section{Results and Discussion}

The superoxide anion production $\operatorname{rate}\left(\mathrm{O}_{2}^{-}\right)$. As showed in Fig.1, compared with the control, at low temperature stress, the $5,10,50$ and $100 \mu \mathrm{mol} / \mathrm{L}$ astaxanthin all can reduce the production rate of superoxide significantly. To some extent, as the treatment concentration increases, the rate of the production is also rising, but the effect of $50 \mu \mathrm{mol} / \mathrm{L}$ is better than $100 \mu \mathrm{mol} / \mathrm{L}$. And at 12 hours of cold treatment, the rate of production is maximized. The results showed that the proper concentration of astaxanthin could effectively reduce the production rate of superoxide anion under cold stress.

Hydrogen peroxide $\left(\mathrm{H}_{2} \mathrm{O}_{2}\right)$. As showed in Fig.2, compared with the control, at low temperature stress, the 5, 10, 50 and $100 \mu \mathrm{mol} / \mathrm{L}$ astaxanthin can reduce the amount of hydrogen peroxide. And with the cold treatment time increases, $\mathrm{H}_{2} \mathrm{O}_{2}$ content also increases. Similar to the superoxide anions, with the increase of astaxanthin content, the effect of removing hydrogen peroxide is better.

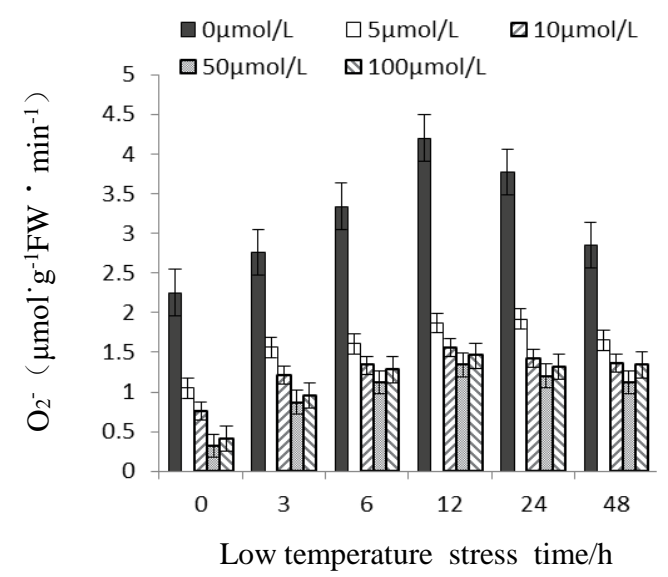

Fig.1 Effect of astaxanthin on the production rate of the oxygenatede in the leaves of

- strawberry seedlings at low temperature stress

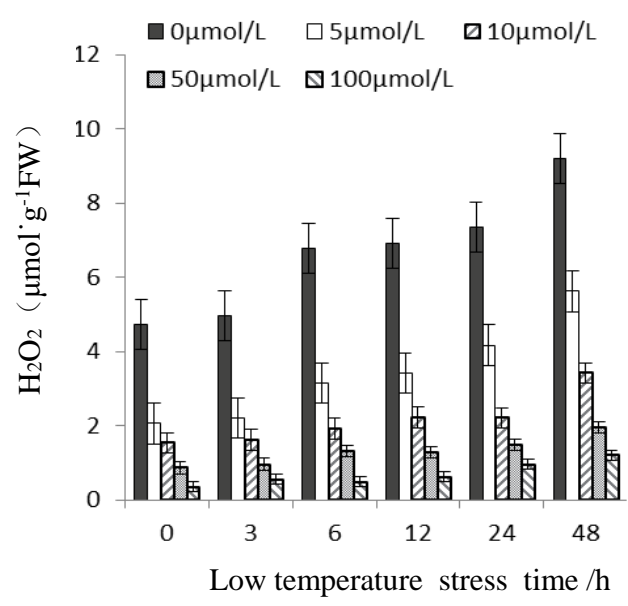

Fig. 2 Effect of astaxanthin on the concent of hydrogen peroxide in the leaves of strawberry seedling at low temperature stress

Activity of protective enzyme activity (SOD 、CAT、POD、APX). As showed in Fig.3, under cold stress, the activity of four antioxidant enzymes SOD, CAT, POD and APX were significantly increased under different concentrations of astaxanthin. However, cold treatment at different times 
did not significantly affect the antioxidant enzyme activities, and there is no obvious change in its laws. Among them, $50 \mu \mathrm{mol} / \mathrm{L}$ treatment had the best effect on the enhancement of SOD and POD activity; however, the optimal concentrations for enhancing CAT and APX activities were $10 \mu \mathrm{mol} / \mathrm{L}$ and $100 \mu \mathrm{mol} / \mathrm{L}$, respectively.
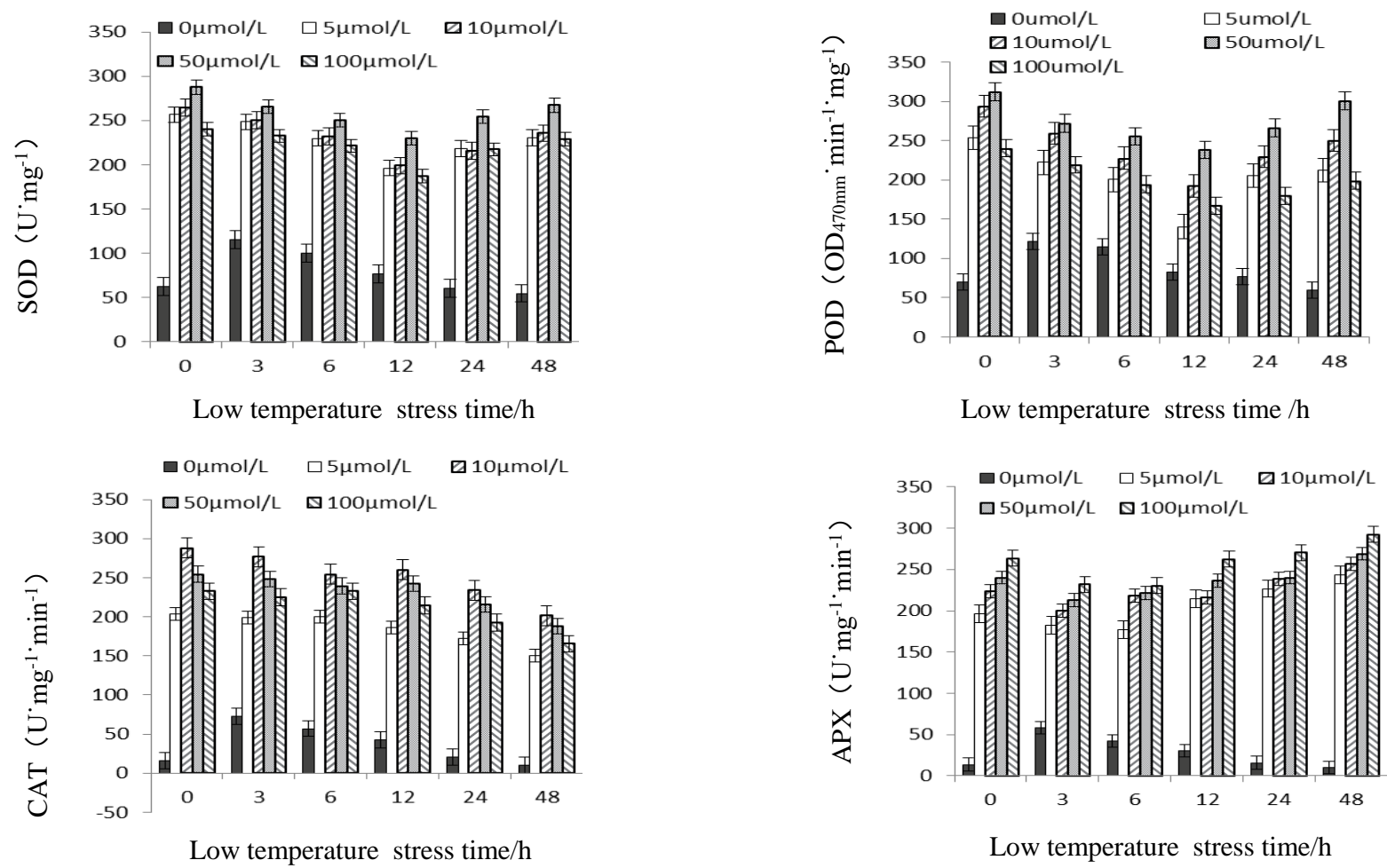

Fig.3 Effects of astaxanthin on the activity of SOD、 rUD、 LA I and ArA III strawberry seedling leaves under low temperature stress

\section{Conclusions}

The damage to plants caused by low temperature stress is derived from membrane system ${ }^{[10]}$. It decreased the activity of the enzymes in plants, and the enzymes can scaveng free radicals; therefore, the accumulation of free radicals is one of the important reasons to damage plants. So, removing radicals such as $\mathrm{O}_{2}{ }^{-}$and $\mathrm{H}_{2} \mathrm{O}_{2}$ in time, and avoiding excessive oxidation of planst cell membrane lipids is crucial. The research data showed that SOD was the enzyme to remove the $\mathrm{O}_{2}^{-}$, while CAT, APX and POD were the key enzymes to remove $\mathrm{H}_{2} \mathrm{O}_{2}{ }^{[11,12]}$. In this experiment, under low temperature stress, compared with the control, the four concentrations of astaxanthin can improve the activity of protective enzymes (SOD、POD、CAT、APX).

Recent research shows that low temperature adversity can promote the accumulation of reactive oxygen $\left(\mathrm{O}_{2}{ }^{-}, \mathrm{H}_{2} \mathrm{O}_{2}\right.$, etc. $)$ and harm plant cells. Therefore, the production rate of $\mathrm{O}_{2}^{-}$and the accumulation of $\mathrm{H}_{2} \mathrm{O}_{2}$ in plants reflect the degree of damage to plants ${ }^{[13-14]}$. In this experiment, under low temperature stress, compared with the control, the four concentrations of astaxanthin can reduce the production rate of $\mathrm{O}_{2}{ }^{-}$and amount of $\mathrm{H}_{2} \mathrm{O}_{2}$.

The results of this study showed that the treatment of astaxanthin can increase the antioxidant capacity of strawberry seedling, and the astaxanthin treatment in suitable concentration can effectively reduce the damage of temperature stress in strawberry seedlings under low temperature stress. Especially, the concentration of $50 \mu \mathrm{mol} / \mathrm{L}$ had the best effect. 


\section{Acknowledgements}

Supported by the Scientific Research Foundation for Returned Overseas Chinese Scholars, State Education Ministry and Key projects of Sichuan Provincial Education Department(172A0319)

\section{References}

[1] Y. Luo. Effects of low temperature stress and exercise on the physiological characteristics of strawberry and the cloning of strawberry chitinase gene [D]. Sichuan Agricultural University. 2007: 26.

[2] L. Y. Yuan. Effects of foreign chemical substances and composite matrix on the anti-cold effect of tomato seedlings [D]. Anhui Agricultural University. 2010, 5: 1.

[3] Y. F. Luo , L. Zhang. Study on the stability of extracts of astaxanthin from shrimp shells [J]. Fujian light spinning, 2008, 11(4): 5-9.

[4] H. T. Geng. Brief introduction of astaxanthin [J]. Chemical education, 2007, 8(3): 5-7.

[5] Lim. B.P , Nagao A, Terao J, et al. Antioxidant activity of xanthophylls on peroxyl radical-mediated phospholipid peroxidation [J]. Biochimica Et Biophysica Acta, 1992, 1126(2): 178 .

[6] S. Y. Tao, J. Ming, Q. Chong. Research advance on the functional characteristics of astaxanthin and its application in functional Food [J]. Food Industry, 2012.

[7] M. J. Zhu, M. H. Zong, Z. Q. Wu, et al. Progress in astaxanthin research [J]. Food industrial technology. 2000, 2(34): 79-81.

[8] Q. L. Dong, X. M. Zhao, H. W. Ma et al. The latest progress in the production of astaxanthin in biotechnology [J]. Biological processing. 2004, 2(2): 18-24.

[9] K. Xu. Effects of external source GA3 and SA on strawberry physiological and biochemical characteristics under $\mathrm{NaCl}$ stress [D]. Gansu Agricultural University. 2006, 5:2-4.

[10] G. H. Fan, F. Jin . Effects of chitosan and salicylic acid on the cold resistance of strawberries [D]. Journal of Gansu Agricultural University. 2008, 4, 2(43): 83-86 .

[11] Asada K. Ascorbatc peroxidasc-a hydrogen peroxide-scavenging cnzymc in plants[J]. Physiol Plant. 1992(58): 235-241.

[12] R. Zhang, J. Lu, Q. S. Mi, et al. Effects of exogenous salicylic acid on antioxidant enzymes of rice seedlings in low temperature $[\mathrm{J}]$. Journal of Southwest agricultural university. Natural science edition.006, 28(1): 29-32, 36.

[13] B. Y. Zhou, L. F. Liang, H. B. Huang, et al. Effects of low temperature and multi-effect azole on superoxide dismutase and abscisic acid in banana and plantain [J]. Journal of Horticulture. 1995, 22(4): 331-335.

[14] L. F. Liang, Z. H. Wang, B. Y. Zhou, et al. Effects of low temperature and multi-effect azole on the peroxidase and isozyme of banana leaves [J]. Journal of South China Agricultural University. 1994, 15(3): 65-70. 